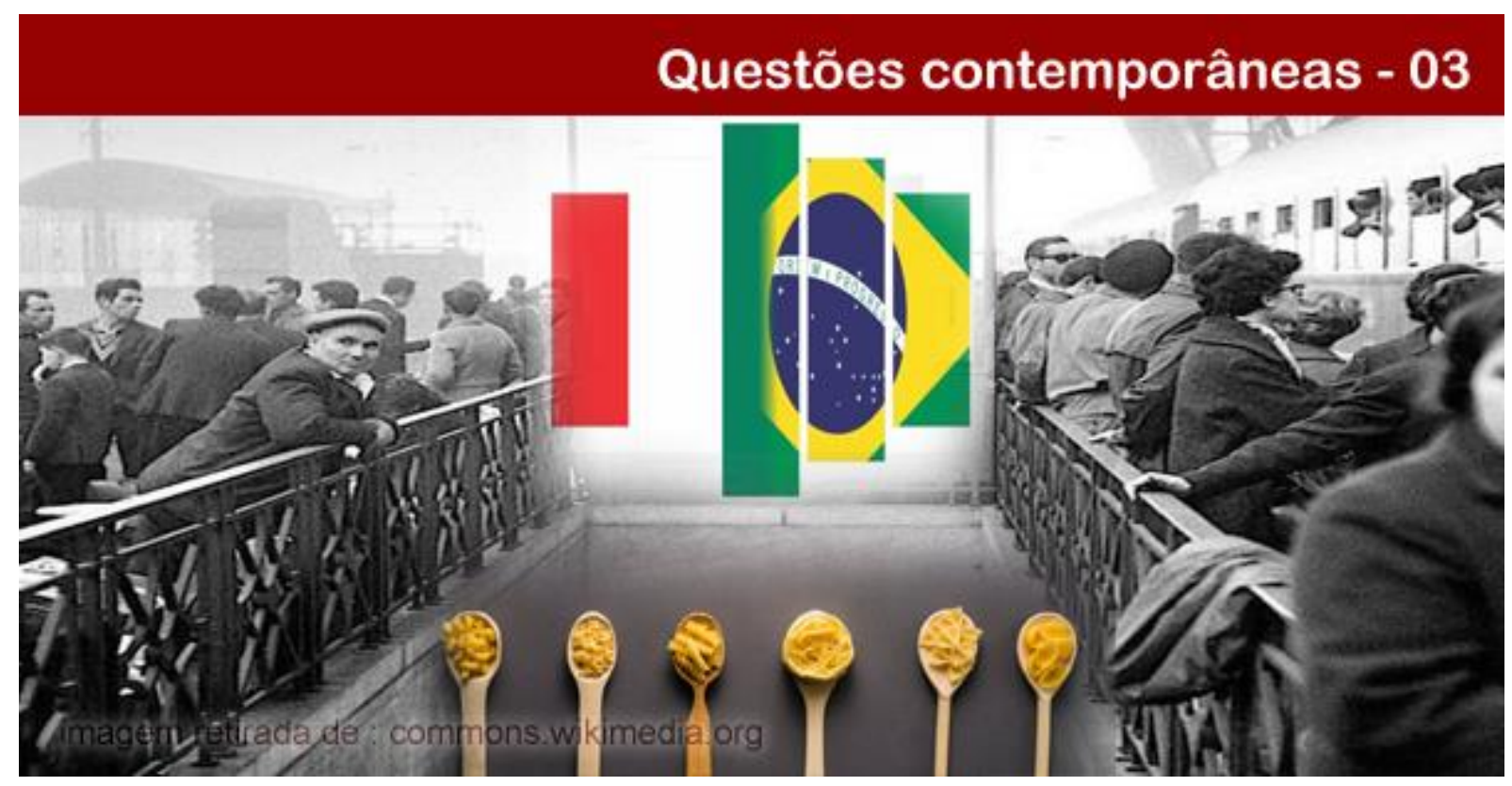

\title{
SOPA, FAMÍLIA E TRABALHO: PERCEPÇÕES CONSTITUÍDAS ENTRE FORQUETA E ITÁLIA
}

\section{Cleber Cristiano Prodanov}

Professor e reitor da Universidade de Feevale. Doutor e Mestre em História Social pela Universidade de São Paulo (USP). Graduado em História pela Universidade do Vale do Rio dos Sinos (Unisinos). E-mail: prodanov@feevale.br.

\section{Magna Lima Magalhães}

Professora da Universidade Feevale. Doutora, Mestre e Graduada em História pela Universidade do Vale do Rio dos Sinos (Unisinos). Líder do grupo de pesquisa Cultura e Memória da Comunidade e coordenadora do Centro de Documentação e Memória-Feevale. E-mail: magna@feevale.br.

\section{Rogério de Vargas Metz}

Professor do curso de Gastronomia do Grupo Uniftec. Doutorando e mestre em Processos e Manifestações Culturais na Universidade Feevale. Graduado em Administração e Gastronomia pela Universidade Feevale. Email: rogerioMetz@feevale.br.

Resumo: Este estudo aborda as percepções de moradores da zona rural de Forqueta, distrito de Caxias do Sul, sobre o alimento. A localidade está inserida na região historicamente conhecida pela imigração italiana do século XIX e integra o roteiro turístico da região serrana do Rio Grande do Sul. Buscou-se, com base na narrativa oral, o recordar de sujeitos que vivenciaram experiências relacionadas à gastronomia italiana e que acionam, a partir de suas lembranças e rememorações, códigos culturais relacionados aos alimentos. Entende-se, de acordo com Alessandro Portelli (1996), que as narrativas apresentam significados individuais relacionados à vivência e à subjetividade de cada indivíduo. Para tanto, lança-se mão da história oral como metodologia de trabalho, o que possibilita conhecer e registrar diferentes manifestações socioculturais. Destacam-se, portanto, no artigo, as percepções e memórias de três descendentes de italianos que viajaram e conheceram o país de seus antepassados, a Itália. Entende-se o alimento como código cultural constituído em uma complexidade histórica e que pode ser relacionado à constituição de identidades e autorrepresentação.

Palavras-chave: Alimento. Memória. Italianos. Imigração.

\section{POLÊM!CA $\mid$ LABORE (}

Polêmica - Revista Eletrônica da Uerj - Rua São Francisco Xavier, 524, $1^{\circ}$ andar bloco D, sl.1001 • Tels.: +55 21 2334-4088/4087 • http://www.e-publicacoes.uerj.br/index.php/polemica/index http://www.labore.uerj.br • laboreuerj@yahoo.com.br 


\section{SOUP, FAMILY AND WORK: PERCEPTIONS BETWEEN FORQUETA AND ITALY}

Abstract: This study approaches the perceptions of residents of Forqueta rural area, Caxias do Sul district, about food. The locality is inserted in the region historically known by the Italian immigration of century XIX and it integrates the itinerary that is in the tourist route of the mountainous region of Rio Grande do Sul. Based on the oral narrative, we sought to recall the subjects who experienced experiences related to the Italian gastronomy and that trigger, from their memories and recollections, cultural codes related to food. According to Alessandro Portelli (1996), it is possible to comprehend that the narratives show individual meanings related to each person experience and subjectivity. Therefore, it was used the oral history as this works methodology, that enables us to know and to register different sociocultural manifestations. Stands out the perceptions and memories of three Italian descendants who had traveled and visited their parent's country, Italy. The foods are understood as a cultural code that was made during a historical complexity and can be related to identity construction and selfrepresentation.

Keywords: Foods. Memory. Italians. Immigration.

\section{Introdução}

Para estudar o alimento como código cultural a partir das experiências alimentares de descendentes de italianos, elencou-se a metodologia da História Oral como caminho de investigação. De acordo com Alberti (2005, p. 164), essa metodologia “é hoje um caminho interessante para se conhecer e registrar múltiplas possibilidades que se manifestam e dão sentidos e formas de vida a escolhas de diferentes grupos sociais, em todas as camadas da sociedade."

Cabe ressaltar que a História Oral como metodologia consolida-se nos espaços de graduação e pós-graduação no Brasil, a partir dos anos 1990, como resultado de discussões sobre renovação historiográfica e novas perspectivas de estudos. O uso da entrevista como fonte de pesquisa se fortalece cada vez mais e legitima a sua importância "para o estudo do passado e do presente nos campos da história e das ciências sociais." (ALBERTI; HEYMANN, 2018, p. 12). Como instrumento, a entrevista possibilita questionar as generalizações sobre o passado, além de ampliar a percepção histórica (ALBERTI, 2005, p. 166) e permitir o acionamento da memória como fenômeno social. De acordo com Bosi (1999, p. 56), “o instrumento decisivamente socializador da memória é a linguagem [...]. As convenções verbais produzidas em sociedade constituem o quadro ao mesmo tempo mais elementar e mais estável da memória coletiva”. Entendendo-a como operação coletiva, a memória possibilita interpretações do passado e permite "tentativas mais ou menos conscientes de definir e reforçar sentimentos de pertencimento" e de "coesão dos grupos e das instituições que compõem a sociedade." (POLLAK, 1989, p. 9).

A interlocução através das entrevistas e o acionamento da memória possibilitam que a pesquisa histórica traga à tona "aspectos da vida da maioria das pessoas que raramente são

\section{POLÊM!CA | LABORE ( (3)}

Polêmica - Revista Eletrônica da Uerj - Rua São Francisco Xavier, 524, $1^{\circ}$ andar

bloco D, sl.1001 • Tels.: +55 21 2334-4088/4087 • http://www.e-publicacoes.uerj.br/index.php/polemica/index http://www.labore.uerj.br • laboreuerj@yahoo.com.br 
bem representados nos arquivos históricos." (THOMPSON, 2002, p. 17). Por essa perspectiva, o estudo ora apresentado está subsidiado na relação da História Oral com a memória, no intuito de pensar o alimento como categoria história a partir do acionamento das lembranças e recordações de descendentes italianos do Rio Grande do Sul, mais especificamente da localidade de Forqueta. As memórias dos entrevistados constituem o jogo relacional entre passado e presente, bem como contribuem e favorecem a construção de identidades vinculadas a dois países: Itália e Brasil.

Cabe destacar que, em 2017, comemorou-se os 142 anos da imigração italiana no sul do Brasil, relembrando a forte presença desta etnia no país. Nesse sentido, Forqueta, uma região administrativa de Caxias do Sul - RS, situada a $15 \mathrm{~km}$ da sede administrativa municipal e considerada um parque temático a céu aberto, entra em foco, já que está inserida no Roteiro Turístico Vale Trentino, onde é possível conhecer cantinas, visualizar o processo de produção de vinhos e sucos, a partir dos cuidados com os parreirais. Atualmente, o distrito é o maior produtor de uvas e vinhos do município de Caxias do Sul, com mais de 150 milhões de litros por ano (CAXIAS DO SUL, 2019).

O nome Forqueta, ao que tudo indica, está relacionado a uma casa de comércio que se situava na Estrada Geral e que conduzia à localidade conhecida como Santos Anjos, cujo desenho se assemelha a uma "forchetta" (garfo em italiano). Elementos culturais vinculados aos imigrantes italianos e a seus descendentes estão presentes na arquitetura das casas e igrejas da região, bem como na culinária "típica italiana" e na religiosidade dos moradores da localidade.

A imigração italiana remete ao século XIX. A partir de 1870, o número de imigrantes no Brasil era significativo e com maior expressão a partir dos anos 80. De acordo com Lucy Hutter (1987), os italianos que seguiram para o Rio Grande do Sul em 1870 eram procedentes de Vicenza, Treviso, Pádua, Verona, Cremona, entre outros locais. Segundo Santos e Zanini (2008, p. 260), “o processo colonizador da região serrana do estado do Rio Grande do Sul começa em 1875 e o da região central, em 1877/78”. Cabe destacar que a saída dos imigrantes da Itália ocorre em meio a um cenário de recém unificação (1870), em que não havia uma identidade italiana elaborada (SANTOS; ZANINI, 2008, p. 262). Sendo assim, a heterogeneidade cultural vinculada às aspirações, aos desejos e aos objetivos devem ser

\section{POLÊM!CA $\mid$ LABORE}


consideradas quando se fala de imigração italiana e da sua presença na formação do regionalismo sul-rio-grandense.

Conforme Boris Fausto (2006),

Depois de 1870 o governo imperial incentivou a vinda de colonos italianos para o Rio Grande do Sul. Pequenos cultivadores procedentes em sua maioria do Tirol, do Vêneto e da Lombardia estabeleceram uma série de colônias, das quais a de Caxias foi a mais importante. Entre 1882 e 1889, em um total de 41 mil imigrantes que ingressaram no Rio Grande do Sul, 34 mil eram italianos. (FAUSTO, 2006, p. 138).

Helena Brum Neto (2012), ao discutir a territorialidade vinculada aos imigrantes alemães e italianos no estado gaúcho, destaca:

Se a migração for considerada como movimento de saída e de chegada, reporta-se também à des-reterritorialização, à transformação, à dinâmica da cultura sobre o espaço e à difusão de culturas e identidades sobre o globo. Ao migrarem, os grupos sociais levam seus costumes e valores, como uma herança, guardando semelhanças e inserindo transformações nos seus patterns culturais. (BRUM NETO, 2012, p. 95).

Dessa forma, os sistemas culturais próprios dos imigrantes tendem a aparecer a partir de sinais exteriores - tais como as práticas alimentares, religiosas e sociais - relacionados a uma coerência e significados que possibilitam situar o imigrante enquanto tal, vinculado às suas origens (CUCHE, 2002, p. 230). Nesse sentido, entende-se que a perspectiva cultural é “como trabalho fronteiriço, que exige um encontro com o 'novo', que não seja parte continuum de passado e presente. Ele cria uma ideia do novo como ato insurgente de tradução cultural". (BHABHA, 2003, p. 27). Para pensar acerca dos elementos culturais vinculados ao alimento como código cultural, elencou-se a narrativa oral como caminho possível para perceber a relação entre passado e presente e sua relação com a dinâmica cultural.

Considerando as narrativas orais como fontes permeadas por diferenças individuais, trabalha-se com o entendimento de que "a história oral e as memórias não nos oferecem um esquema de experiências comuns, mas sim um campo de possibilidades compartilhadas, reais ou imaginárias" (PORTELLI, 1996, p. 8). O significado da experiência está associado ao ato de recordar, contar e interpretar. Sendo assim, acionam-se atores sociais que vivenciaram experiências carregadas de significados (PORTELLI, 1996, p. 9). Compreende-se, dessa forma, que história e memória constituem-se em cenários culturais privilegiados, pois são distintas e radicalmente imbricadas (NEVES, 2009, p. 26). Assim, neste estudo, prima-se

\section{POLÊM!CA $\mid$ LABORE}


pelas vivências e experiências de três entrevistados ${ }^{1}$ que nasceram na área rural da região serrana do Rio Grande do Sul, caracterizada pela presença marcante da imigração italiana desde 1875 (século XIX), onde elementos culturais próprios estão presentes na arquitetura, no cuidado com os vinhedos, além de marcar a gastronomia regional com os "típicos pratos italianos", que servem de atrativo turístico.

A interlocução estabelecida com os entrevistados priorizou os moradores de Forqueta com mais de 45 anos que, em algum momento de suas vidas, tenham conhecido a Itália. Para as entrevistas, que foram gravadas e posteriormente analisadas, seguiu-se um roteiro (questionário semiestruturado). As interpretações das entrevistas instigam a pensar sobre elementos culturais relacionados ao alimento como categoria histórica e constituinte de memória coletiva.

De acordo com Santos e Zanini (2008, p. 257), “a comida assume um papel muito importante na construção das memórias coletivas destes grupos que, marcados por rupturas, passadas e presentes, elaboram sinais diacríticos específicos como demarcadores de seus pertencimentos e origens". Nesse contexto, como dito anteriormente, o presente estudo busca pensar sobre o alimento como categoria histórica e, portanto, envolto por uma dinâmica social permeada por práticas sociais que refletem condutas e costumes (SANTOS, 2005).

Procurou-se, então, através das narrativas de nossos interlocutores, possibilidades de refletir acerca da relação constituinte entre passado e presente, a fim de pensar sobre a comida e seus (re)significados a partir da dinâmica cultural. Nessa perspectiva, este artigo investiga a comida como manifestação cultural e suas especificidades na localidade de Forqueta, área rural da região serrana do Rio Grande do Sul.

\section{Rememorações e comida}

As histórias passadas de geração em geração pelos descendentes de imigrantes italianos, no geral, remetem, principalmente, às dificuldades encontradas ao chegar à nova terra (Brasil). Quando as memórias e lembranças dos entrevistados foram acionadas, os problemas enfrentados pelos seus antepassados aparecem. O espectro e a mescla de dificuldades de ordem econômica, social e cultural estão presentes em suas memórias,

\footnotetext{
${ }^{1}$ Ao apresentar trechos das narrativas orais, optou-se por deixar a redação conforme gravação realizada, com exceção de pequenos ajustes na pontuação e na concordância verbal.
}

\section{POLÊM!CA $\mid$ LABORE}


"costuradas" com um tempo em que ouviam as histórias dos nonos ${ }^{2}$ e dos pais. Tais rememorações remetem à Itália do final do século XIX, marcada por conflitos e por muitas desigualdades. Uma das falas indica que "foi bem difícil, porque chegaram e não tinha nada além de uns galhos de árvore pra eles dormi"3 e indica que "saíram de lá (Itália) porque faltava até comida" 4 .

As agruras sofridas pelos primeiros imigrantes ao chegarem à terra desconhecida está intrinsecamente relacionada à fome. A penúria está, muitas vezes, associada à Itália e sua realidade sociopolítica, à consequente saída dos antepassados da terra natal em busca de oportunidades (terra e trabalho) e também às dificuldades encontradas ao chegarem ao Brasil.

A polaridade entre escassez/fome e fartura está mediada pelo trabalho vinculado à terra como valor importante e norteador da trajetória dos emigrados e seus descendentes, assim como também estão presentes a gradativa fartura de alimentos cultivados e a melhoria na alimentação. Por essa perspectiva, o trabalho produtivo, a lida com a terra e as características dos colonos estabelecem rupturas e processos de transformações e alterações em meio a uma relação dialógica entre escassez e abundância, que estabelece sentidos a uma carga simbólica que constitui o ser ítalo-gaúcho na localidade em estudo. Dessa forma, o acionamento da fartura (mesa farta) é uma marca dos "italianos" e seus descendentes, vinculada ao trabalho árduo e à dedicação à terra. A produção de alimentos é, pois, correlata das virtudes constituintes de uma distinção social; o colono, "que se torna categoria social", além de "sinônimo de agricultor de origem europeia, numa gênese remonta ao processo histórico de colonização” (SEYFERTH, 1993, p. 41).

Segundo Santos e Zanini (2008, p. 257), "para os italianos no Rio Grande do Sul, a comida farta e forte foi e ainda é um importante demarcador étnico. Ela deve ser servida à mesa, em exposição de abundância e trabalho produtivo. Serve para o paladar e para os olhos também". As autoras mencionam, ainda, que a comida e o apelo à fartura são, por exemplo, centrais na propaganda da tradicional Festa da Uva em Caxias do Sul, sendo o mote principal "a mesa farta", divulgada em cartazes, folders e cartões postais (SANTOS; ZANINI, 2008, p. 266). Nesse contexto, Caxias do Sul destaca-se como uma cidade da região colonial italiana

\footnotetext{
${ }^{2}$ Expressão usada pelos descendentes de imigrantes italianos moradores do distrito de Forqueta e seus familiares quando se referem a seus avós ou bisavós.

3 LANGO, Maria Helena. [Mai. 2018]. Entrevistador: Rogério de Vargas Metz. Caxias do Sul - RS, 2018. 1 arquivo em mp3. Entrevista concedida a Rogério de Vargas Metz.

${ }^{4}$ Id., 2018.
}

\section{POLÊM!CA $\mid$ LABORË}

Polêmica - Revista Eletrônica da Uerj - Rua São Francisco Xavier, 524, $1^{\circ}$ andar

bloco D, sl.1001 • Tels.: +55 21 2334-4088/4087 • http://www.e-publicacoes.uerj.br/index.php/polemica/index

http://www.labore.uerj.br • laboreuerj@yahoo.com.br 
do Rio Grande do Sul, marcada, desde o início do século XIX, por experimentos precursores no plantio de vinhas italianas, que se intensificaram com a chegada das primeiras levas de imigrantes protagonistas do processo de colonização planejada, a partir de 1875, para o povoamento de regiões até então desabitadas (PELLANDA, 1950, p. 42 apud RUGGIERO, 2018, p. 127).

Dentre os alimentos mencionados pelos entrevistados e que possibilitam pensar acerca de códigos culturais está a sopa. Mencionada nas três entrevistas realizadas, a sopa é percebida como alimento fundamental, que "não pode faltar" e que agrada o paladar. Vinculado a um passado de dificuldades e escassez, esse alimento muitas vezes foi, segundo as memórias, o "único alimento a ser servido". A sopa de agnoline (também conhecida como capelleti) sinaliza para um sentimento de afetividade, um elo entre passado e presente, capaz de acionar memórias que trazem à tona as conquistas realizadas a partir do trabalho dos antepassados, responsáveis pelo início de tudo. Hoje é o prato que não pode faltar em festas comunitárias e almoços familiares, porém, contrariando outros tempos (de escassez), é a abertura/entrada para a mesa farta.

Portanto, novos sentidos cercam a sopa italiana e se distanciam das dificuldades de outrora, o que fica evidente no trecho da entrevista de Itamyra $^{5}$ (82 anos), que rememora as histórias de suas nonas, as quais contavam que os "bisa", ao chegarem ao Brasil, "não tinham nada" e "comiam mais caça". Nas rememorações, está presente, ainda, a ideia de escassez na frase "a gente comia um ovo em sete pessoas" ou quando menciona que o bisavô "não tinha nada e fizeram tudo" ", trazendo à tona a sopa de feijão como único alimento à noite, no jantar, e fundamental para saciar o corpo com fome. Nesse sentido, o feijão, além de ser fonte de energia, por meio de seus nutrientes, é um ato alimentar que "implica também valoração simbólica” (MENASCHE, 2004, p. 114).

Questionada sobre a comida e suas impressões durante a viagem realizada à Itália, Itamyra comenta que sentiu falta da carne de gado, posto que em suas saídas (passeios) encontrava mais a carne de porco. Talvez, o fato de conhecer o país de seus antepassados, de acordo com ela há mais ou menos 15 anos, dificulte as memórias e lembranças acerca da culinária. Conforme Barros, a memória deve "ser compreendida como território, como espaço

\footnotetext{
${ }^{5}$ Entrevista concedida por BAMPI, Itamyra Tonietto. [Mai. 2018]. Entrevistador: Rogério de Vargas Metz. Caxias do Sul - RS, 2018. 1 arquivo em mp3.

${ }^{6}$ Id., 2018.
}

\section{POLÊM!CA $\mid$ LABORE}


vivo, político e simbólico, no qual se lida de maneira dinâmica e criativa com as lembranças e com os esquecimentos que reinstituem" (BARROS, 2009, p. 37, grifo do autor).

As dificuldades enfrentadas pela sua família, os cuidados dos pais com os filhos, bem como os laços familiares evidenciam-se na entrevista de Itamyra, sem se esquecer da ausência da mãe, ao que tudo indica, por "ela estar sempre doente" e o pai cuidar "dela [da mãe] e oitos irmãos". As memórias relacionadas à comida e à falta dela também estão entrelaçadas com o trabalho e a organização familiar. Ao destacar os cuidados do pai com a mãe, a interlocutora instiga a pensar na organização das tarefas entre os componentes da família, na relevância do papel da mulher no comando das tarefas domésticas, no cuidado com os filhos, entre outros. Assim, é possível perceber, a partir de Santos e Zanini (2008, p. 259), que os domínios domésticos estão "imbricados pelas relações de gênero, etárias, hierárquicas e outras que mostram que a comida é um processo que depende da organização do trabalho familiar e coletivo, especialmente entre camponeses".

A polenta ${ }^{7}$ é outro alimento associado à cozinha italiana, como sendo uma marca. Sua elaboração, como mencionado em uma entrevista, já não é realizada como outrora, posto que em tempos pretéritos mexer a farinha em um tacho sem parar era a prática. Helena ${ }^{8}, 75$ anos, diz: “A polenta eu já não faço mais como os nonos, que nem a minha mãe fazia. Minha mãe mexia todo tempo e com a panela dentro do fogo". Esse alimento também é lembrado como substituto do pão em outros tempos, já que a sua produção era, muitas vezes, inviabilizada pelas dificuldades de obter o trigo, o que talvez esteja vinculado à dificuldade de plantio e valor oneroso do produto. Já o milho, ao que tudo indica, era muito mais fácil de ser cultivado e melhor aproveitado no cotidiano.

Sorcinelli (1998) menciona a importância do milho e relaciona a utilização do grão pelos italianos. Segundo o autor, eles viviam sem riquezas, eram pobres, mas não passavam fome, posto que o milho era uma alternativa para grande parte da população devido à dependência de cereais tradicionais. $O$ estudioso acrescenta, ainda, que "o milho e a batata quebram, sem dúvida, o círculo vicioso da escassez de víveres e epidemias", fazendo referência à Europa (SORCINELLI, 1998, p. 792).

\footnotetext{
7 Mistura de farinha de milho com água. É um alimento consumido em muitas regiões do Brasil, mas principalmente no Rio Grande do Sul, Santa Catarina e Paraná.

${ }^{8}$ LANGO, 2018, passim.
}

\section{POLÊM!CA $\mid$ LABORE}


É importante ressaltar que a integração de diferentes continentes através das rotas comerciais, principalmente a partir do século $\mathrm{XV}$, acarreta em novidades alimentares. Alimentos, como o tomate, a batata e o milho, tornam-se mais importantes na alimentação ocidental desde os séculos XIX e XX (FLANDRIN; MONTANARI, 1998, p. 532). Os encontros culturais empreendidos, a partir das rotas comerciais e da expansão marítima através do Atlântico, fomentaram, pois, mudanças e alterações na alimentação europeia.

As memórias dos entrevistados permitem pensar nas famílias compostas de muitos filhos (entre 7 e 8) e os cuidados dos mais velhos para com os mais novos enquanto os pais trabalhavam na terra e nas lidas domésticas. Tais rememorações são acionadas principalmente quando mencionam alimento e trabalho. A relação familiar, o vínculo de atividades e distribuição de tarefas cotidianas trazem à tona as mudanças sociais através de uma progressiva alteração geracional, ou seja, o trabalho e a atuação da família são "ingredientes" que reverteram a miséria na fartura conquistada e em melhor qualidade de vida das últimas gerações.

Outro alimento presente nas falas dos entrevistados, são as massas e suas variedades, consideradas a principal comida, que não pode faltar na cozinha dos descendentes. Uma das entrevistadas remete à sua experiência com esse prato na Itália e a proximidade com o Brasil, evidenciando, entretanto, a diferença de temperos, como o uso de ervas (menciona o manjericão) nos molhos que acompanham as massas, o que não é comum nos hábitos alimentares da região de Forqueta, onde mora.

Essa referência às massas e seus temperos "fortes", como a sálvia, por exemplo, também aparece na fala de outro interlocutor, Berttoti, 49 anos, que, como as demais entrevistadas, nasceu na zona rural de Caxias do Sul e trabalha com o cultivo de uvas e figos. O descendente menciona que os bisavôs vieram da Itália. Ao falar de suas impressões sobre os dias em que passou no país europeu, sinaliza que a terra e o clima chamaram muito a sua atenção (foi do que ele mais gostou), bem como o cuidado com as uvas e os vinhos. E sobre os alimentos, Berttoti ${ }^{9}$ diz que as comidas servidas nas cantinas italianas são próximas das preparadas no Brasil.

É interessante perceber que as impressões positivas por parte do entrevistado em relação à Itália ficaram limitadas, principalmente, à terra e ao clima, o que é traduzido na

\footnotetext{
${ }^{9}$ Entrevista concedida por BERTOTTI, Irineu. [Abril/2017] Entrevistador: Rogério de Vargas Metz. Caxias do
} Sul - RS, 2017. 1 arquivo em mp3

\section{POLÊM!CA $\mid$ LABORE}


vontade de retornar ao Vêneto (região do nordeste da Itália). Em relação à comida, o entrevistado menciona não ter encontrado alimentos muito diferentes, transmitindo a ideia de ter levado consigo para a Itália algumas expectativas sobre a culinária e a gastronomia, as quais não foram atendidas. Para ele, a comida era muito parecida (com a do Brasil) e as pizzas não eram "assim muito diferentes". Cabe ressaltar que o gosto e as classificações do que é bom ou ruim em relação à comida estão vinculados ao "patrimônio cultural das sociedades humanas" e podem ser alterados e modificados com o tempo (MONTANARI, 2008, p. 95).

Dessa forma, entende-se que a tradição, apesar de ser dinâmica, serve como "cimento de coesão grupal” (HOBSBAWM, 1997, p. 21), já que está vinculada à memória coletiva. Nessa assertiva, ao discutir as tradições gaúchas, Caroline Luvizotto (2010, p. 65) assevera que "a tradição coordena a ação que organiza temporal e espacialmente as relações dentro da comunidade e é um elemento intrínseco e inseparável da mesma".

Berttoti reitera, ainda, que a sopa é uma tradição italiana (capeletti, agnoline), principalmente em momentos de festas na comunidade. Segundo ele, "se faltou a sopa, já não é festa de comunidade". Outro aspecto indicado pelo entrevistado, associado à tradição, bem como à comida, é a reunião familiar para o almoço de domingo. Segundo ele, é "uma tradição a família se reunir, meu pai gostava de reunir os filhos, os tios"10. Também em sua fala vem à tona a importância das mulheres coordenando cozinhas, cuidando dos irmãos e irmãs mais novos na ausência da mãe, bem como na transmissão de conhecimentos através de gerações, entre eles o preparo dos alimentos. Percebe-se, dessa forma, na interlocução com os entrevistados, a relevância do papel da mãe, a responsável pelo "ato de cozinhar" e pela transmissão de saberes tradicionais étnicos (SEYFERTH, 2015).

A comida envolve o preparo e a degustação, promovendo momentos de socialização o que é fundamental em meio às famílias de descendentes de imigrantes italianos -, bem como o vínculo comunitário e as relações cotidianas com o trabalho no cultivo da terra. Entende-se, nesse sentido, que "a comensalidade entre os participantes remete a expressões da solidariedade básica do grupo familiar ou da comunidade" (JOANNÉS, 1998, p. 57).

Importante destacar, também, a relação entre alimentação e religiosidade, expressa na fala dos entrevistados ao mencionarem a reunião das pessoas para festejar e agrupar a comunidade. A partir dos princípios católicos, um padroeiro, como, por exemplo, São

${ }^{10}$ BERTOTTI, 2018. Passim.

\section{POLÊM!CA $\mid$ LABORE}

Polêmica - Revista Eletrônica da Uerj - Rua São Francisco Xavier, 524, $1^{\circ}$ andar

bloco D, sl.1001 • Tels.: +55 21 2334-4088/4087 • http://www.e-publicacoes.uerj.br/index.php/polemica/index

http://www.labore.uerj.br • laboreuerj@yahoo.com.br 
Virgílio, reúne e agrega a comunidade que compartilha momentos de socialização e de produção da comida a ser servida a todos. A motivação é a homenagem ao padroeiro, que possibilita momentos de trocas e compartilhamentos daqueles que professam a mesma fé e devoção e se reconhecem como iguais a partir de elementos étnicos e identitários. Além disso, a experiência de quem sabe e gosta de cozinhar é bem recebida. Nesses eventos, a sopa de agnoline de massa "fresca", preparada de forma artesanal, não pode faltar e está no roteiro de preparação do encontro, da festa, como muito aguardado.

Segundo Maciel (2005, p. 49), “as identidades sociais/culturais relacionadas à alimentação constituem-se em espaços privilegiados para apreender determinados processos, através dos quais os grupos sociais marcam sua distinção, se reconhecem e se veem reconhecidos".

Helena, outra entrevistada, viajou por diferentes regiões da Itália (Roma, Veneza, Florença e Toscana) e ressalta que passou 18 dias no país e gostou muito - segundo ela, fez "uma visita técnica" para conhecer a agricultura, as cantinas, vinhedos, entre outros. Durante a conversa, mencionou o comentário de uma comerciante italiana (de uma loja) referindo-se ao Brasil como um país lindo, "melhor que a Itália". Questionada sobre o comentário, a interlocutora afirma concordar, dizendo que o Brasil é "bem melhor que a Itália" e acrescenta que, apesar de ter gostado muito da viagem, prefere o Brasil. A sua "brasilidade" aparece no prato "típico brasileiro" como preferido e presente no cotidiano: o arroz e feijão que não podem faltar. Por outro lado, sinaliza que, nos encontros familiares e de sociabilidade em que reúne filhos, netos e irmãos, as massas e os risotos sobressaem no cardápio.

Sobre a reunião familiar e a relação com o alimento, é importante mencionar que o ato de "comer não é um ato solitário ou autônomo do ser humano, ao contrário, é a origem da socialização" (CARNEIRO, 2005, p. 71). Além disso, fortalece e ressignifica elementos socioculturais que constituem uma identidade, já que a constituição da mesma ocorre através de processos inconscientes, pois não é "algo inato, existente na consciência no momento do nascimento, mas sim como um processo em andamento" (HALL, 2004, p. 38).

Os elementos da pauta cultural do ser brasileiro através da comida estão presentes no cotidiano de Helena através do "arroz e feijão", enquanto os do "ser italiano", vinculados ao histórico da imigração, estão presentes nos risotos e massas compartilhados nas reuniões familiares. Dessa forma, há um diálogo entre diferentes códigos culturais presentes em um

\section{POLÊM!CA $\mid$ LABORE}


jogo relacional constituinte de identidades permeadas por uma formação complexa de elementos alterados, modificados e ressignificados em um processo histórico no qual a interação social está estreitamente ligada a uma identidade social coletiva e de autorrepresentação.

\section{Considerações finais}

A partir da História Oral e considerando as experiências individuais comuns e compartilhadas, buscou-se refletir sobre o alimento como uma categoria histórica e, portanto, inserida em uma relação de temporalidade (passado e presente) que instiga a pensar sobre elementos culturais, bem como sobre a dinâmica de construção de identidades a partir das memórias de descendentes de imigrantes italianos que tiveram a oportunidade de conhecer o país de origem de seus antepassados, a Itália.

A partir das narrativas registradas através da história oral, foram apresentadas três entrevistas, as quais remetem às dificuldades encontradas pelos primeiros imigrantes ao chegarem ao Brasil e à escassez de alimento que permeia a saída da Itália. Associadas aos tempos pretéritos estão as agruras enfrentadas pelos "bisas" e pelos "nonos", bem como o esforço através do trabalho para modificar a situação dos familiares. As conquistas gradativas vinculadas ao cultivo da terra presente, a ressignificação, não somente de alimentos, como a sopa, abordada como um código social e cultural, tornam-se marca da italianidade, presente no ser descendente de italianos.

Portanto, fica evidenciado nas narrativas que o trabalho vinculado à terra é norteador das conquistas ao longo do tempo através do esforço de diferentes gerações, o que reflete na fartura da mesa dos descendentes de italianos. Os momentos de sociabilidade e compartilhamento de alimentos "tipicamente italianos" (sopas, massas, polenta, entre outros) são práticas culturais presentes e ressignificadas em um processo histórico permeado pela dinamicidade. Ou seja, mais que simples alimento para sustentar o corpo, a comida pode ser entendida como elemento cultural vinculado às memórias e à construção histórica, bem como constituinte de identidades que se configuram a partir de pautas culturais diversas e que permitem uma autorrepresenção forjada a partir da complexidade de diferentes manifestações culturais.

\section{POLÊM!CA $\mid$ LABORE}


Através da comida como código cultural, foi possível perceber o jogo relacional dos entrevistados ao se reconhecerem como italianos e brasileiros, já que suas memórias e suas experiências estão vinculadas a um processo histórico que traz à tona elementos renovados no cotidiano sobre a trajetória dos antepassados e seu legado com a comida e o trabalho, por exemplo, ao mesmo tempo em que tais elementos estão vinculados ao Brasil (ao ser brasileiro) e às oportunidades de acesso à terra e à fartura. O recordar, no presente estudo, acionou memórias dos interlocutores "recheadas de sabores" que permeiam a história dos descendentes de italianos nas terras brasileiras e que mostram a importância do alimento em meio à dinâmica social.

\section{Referências}

ALBERTI, V.; HEYMANN L. Acervos de história oral: Um patrimônio silencioso. IN: BAUER, L.; BORGES, V. T. (Org.). História Oral e patrimônio cultural: potencialidades e transformações. São Paulo: Letras \&Voz, 2018.

ALBERTI, V. História dentro da História. In: PINSKY, C. B. (Org.). Fontes históricas. São Paulo: Contexto, 2005.

BARROS, J. A. História e Memória - uma relação na confluência centre tempo e espaço tempo. MOUSEION, v. 3, n. 5, p. 35-67, jan./ jul. 2009.

BHABHA, H. K. O local da cultura. Belo Horizonte: UFMG, 2003.

BOSI, E. Memória e Sociedade: Lembranças de velhos. São Paulo: Cia. das letras, 1999.

BRUM NETO, H. B. Os territórios de imigração alemã e italiana no Rio Grande do Sul. 2012. 318 f. Tese (Doutorado em Geografia) - Faculdade de Ciências e Tecnologia, Universidade Estadual Paulista Júlio de Mesquita Filho, Presidente Prudente, 2012.

CARNEIRO, H. S. Comida e Sociedade: Significados sociais na história da alimentação. História: Questões \& Debates, n. 42, p. 71-80, 2005.

CAXIAS DO SUL. Prefeitura Municipal de Caxias do Sul. Forqueta. Disponível em:

<https://caxias.rs.gov.br/gestao/subprefeituras/forqueta>. Acesso em: 30 dez. 2018.

CUCHE, D. O conceito de cultura em Ciências Sociais. Bauru: Edusc, 2002.

FAUSTO, B. História concisa do Brasil. São Paulo: Efusp, 2006.

FLANDRIN, J. L.; MONTANARI, M. História da alimentação. São Paulo: Estação Liberdade, 1998.

HALL, S. A identidade cultural na pós-modernidade. Rio de Janeiro: DP\&A Editora, 2004.

HOBSBAWM, E. A invenção das tradições. Rio de Janeiro: Paz e terra, 1997.

\section{POLÊM!CA $\mid$ LABORE}

Polêmica - Revista Eletrônica da Uerj - Rua São Francisco Xavier, 524, $1^{\circ}$ andar

bloco D, sl.1001 • Tels.: +55 21 2334-4088/4087 • http://www.e-publicacoes.uerj.br/index.php/polemica/index

http://www.labore.uerj.br • laboreuerj@yahoo.com.br 
HUTTER, Lucy M. Imigração italiana: aspectos gerais do processo imigratório. Revista do Instituto de Estudos Brasileiros, São Paulo, n. 27, p. 59-73, 1987. Disponível em: <http://www.revistas.usp.br/rieb/article/view/69906>. Acesso em: 15 out. 2018.

JOANNÉS, F. A função social do banquete nas primeiras civilizações. In: FLANDRIN, J.-L.; MONTANARI, M. História da alimentação. São Paulo: Estação Liberdade, 1998.

LUVIZOTTO, C. K. As tradições gaúchas e sua racionalização na modernidade tardia [online]. São Paulo: Editora UNESP; São Paulo: Cultura Acadêmica, 2010. 140 p. E-book. Disponível em: <http://books.scielo.org/id/cq8kr/pdf/luvizotto-9788579830884.pdf>. Acesso em: 20 out. 2018.

MACIEL, M. E. Olhares antropológicos sobre alimentação. Identidade Cultural e alimentação. In: CANESQUI, A. M.; GARCIA, R. W. D. (Org.). Antropologia e nutrição: um diálogo possível [online]. Rio de Janeiro: Editora Fiocruz, 2005. E-book. Disponível em: <http://books.scielo.org/id/v6rkd/pdf/canesqui-978857541387603.pdf >. Acesso em: 24 out. 2018.

MENASCHE, R. Risco à mesa: alimentos transgênicos, no meu prato não? Campos - Revista de Antropologia, Curitiba, v. 5, n. 1, p. 111-129, 2004.

MONTANARI, M. Comida como cultura. São Paulo: Senac-SP, 2008.

NEVES, M. S. Nos compassos do tempo. A História e a cultura da memória. In: SOHIET, R.; ALMEIDA, M. R. C.; AZEVEDO, C.; GONTIJO, R. (Org.). Mitos, projetos e práticas políticas. Memória e Historiografia. Rio de Janeiro: Ed. Civilização Brasileira, 2009.

POLLAK, Michel. Memória, Esquecimento, Silêncio. Revista Estudos Históricos, Rio de Janeiro, v. 2, n. 3, p. 3-15, 1989.

PORTELLI, A. A filosofia e os fatos. Narração, interpretação e significado nas memórias e nas fontes orais. Revista Tempo, Rio de Janeiro, v. 1, n. 2, p. 59-72, dez. 1996.

SANTOS, C. R. A alimentação e seu lugar na história: os tempos da memória gustativa. História: Questões \& Debates, Curitiba, n. 42, p. 11-31, 2005.

SANTOS, M. O.; ZANINI, M. C. Comida e simbolismo entre imigrantes italianos no Rio Grande do Sul (Brasil). Caderno Espaço Feminino, v. 19, n. 1, p. 255-284, jan./ jul. 2008.

SEYFERTH, G. Identidade Camponesa e Identidade Étnica (Um estudo de caso). Anuário Antropológico, Brasília, v. 91, p. 31-63, 1993.

A colonização alemã em Santa Catarina: hábitos alimentares e etnicidade. In: MENASCHE, R. Saberes e Sabores de Colônia. Porto Alegre: UFRGS, 2015.

RUGGIERO, A. A saudade dos sabores e o comércio étnico dos imigrantes italianos no Brasil (1875-1914).

Revista Prâksis, v. 15, n. 1, jan./ jun. 2018.

SORCINELLI, P. Alimentação e Saúde. In: FLANDRIN, J.-L.; MONTANARI, M. História da Alimentação. São Paulo: Estação Liberdade, 1998. p. 792-805.

THOMPSON, Paul. História oral e contemporaneidade. História Oral. Revista da Associação Brasileira de História Oral, São Paulo, n. 5, p. 9-28, jun. 2002.

Recebido em: 19/11/2018.

Aceito em: 30/12/2018.

\section{POLÊM!CA $\mid$ LABORE}

Polêmica - Revista Eletrônica da Uerj - Rua São Francisco Xavier, 524, $1^{\circ}$ andar

bloco D, sl.1001 • Tels.: +55 21 2334-4088/4087 • http://www.e-publicacoes.uerj.br/index.php/polemica/index

http://www.labore.uerj.br • laboreuerj@yahoo.com.br 